\title{
Grape marc, wine lees and deposit of the must: How to manage oenological by-products?
}

\author{
Valérie Lempereur ${ }^{\mathrm{a}}$ and Sophie Penavayre \\ Institut Français de la Vigne et du Vin (IFV), 210 boulevard Vermorel, 69661 Villefranche sur Saône Cedex, France
}

\begin{abstract}
Winemaking produces solid (grape marc) and liquid (wine lees and deposit of the must) wastes named "oenological by-products", which, according to European regulations, must be eliminated following the environmental regulatory requirement [1]. In France, these European regulations forced wine growers, until the 2013/2014 campaign, to deliver all by-products to wine distilleries. This French obligation is known as the "prestation vinique" [2,3]. Following the Common Market Organisation wine reform, a consultation was initiated by FranceAgriMer on the potential value of oenological by-products. The French Institute of Vine and Wine (IFV) coordinated a national experimentation from 2010 to 2013 about recovery of by-products, with the support of members of the Technical Group: Association des Viticulteurs d'Alsace (AVA), Comité Interprofessionnel du Vin de Champagne (CIVC), Institut Technique des Corps Gras (ITERG), et Union Nationale des Groupements de Distillateurs d'Alcool (UNGDA). Distillation of grape marc and wine lees spreading and composting, and anaerobic digestion of grape marc were studied in order to answer the following questions: What technical feasibility? What environmental impact? What cost for winegrowers? What conformity with the regulations, including environmental regulatory obligations? [4].
\end{abstract}

\section{Introduction}

The national experimentation on the recovery of byproducts studied the current itinerary for treatment (distillation) and three forward-looking scenarios for grape marc recovery: spreading, composting and anaerobic digestion.

Technical and organizational feasibility of alternative scenarios have been studied (laboratory measurements, tests at exploitation and industrial scales). Then, based on recommendations from technical tests and current regulations, scenarios have been developed considering different scales and configurations of by-products recovery (individual or collective spreading and composting, "at farm" or industrial anaerobic digestion). These scenarios had then been used to study the cost of each type of recovery method for a winegrower, and the environmental impact of each sector (Life Cycle Analysis method, ISO 14 040).

Technical and organizational feasibility of distillation, current itinerary, have not been studied. Only the economic and environmental studies have been conducted on this recovery method. Results are presented for each recovery method.

\footnotetext{
${ }^{a}$ Corresponding author: valerie. lempereur@vignevin.com
}

\section{Technical aspects}

\subsection{Distillation and its by-products}

\subsubsection{French wine distilleries: Territorial coverage and deposits treated}

About 50 wine distilleries are present on the French territory. They collect oenological by-products in an average radius of $50 \mathrm{~km}$ around their site. The 50 wine distilleries collect and recover each year about 850000 tons of grape marc (including their juices drip) and 1.4 million hectoliters of wine lees and deposits of the must.

\subsubsection{The distillation's by-products}

Wine distilleries recover grape marc, wine lees, deposits of the must and wines in various by-products every year: grape seed, standardized fertilizers and organic amendments, alcohols, lime tartrate ... which are used as raw material in various sectors: agriculture and viticulture, food industry, cosmetic and chemical industries and energy.

\subsection{Grape marc spreading}

\subsubsection{Analytical characteristics}

Grape marc agronomical characteristics have been studied at national scale between 2010 and 2012 from 22 specimens sampled in 8 production regions. A specific study has also been conducted from 25 specimens from

This is an Open Access article distributed under the terms of the Creative Commons Attribution License 4.0, which permits unrestricted use, distribution, and reproduction in any medium, provided the original work is properly cited. 
Table 1. Agronomic composition of 22 specimens of grape marc sampled in 8 production regions.

\begin{tabular}{|l|c|c|c|c|c|}
\hline & Average & Min & Max & $\begin{array}{c}\text { Coefficient } \\
\text { of variation }\end{array}$ & Limit $^{a}$ \\
\hline $\begin{array}{l}\text { Dry matter } \\
(\%)\end{array}$ & 37.2 & $26.1^{b}$ & 54.1 & $19 \%$ & $\geq 30$ \\
\hline $\mathrm{pH}$ & 3.89 & 2.40 & 6.50 & $18 \%$ & \\
\hline $\begin{array}{l}\text { Organic } \\
\text { matter } \\
(\mathrm{g} / \mathrm{kg})\end{array}$ & 340 & 237 & 466 & $17 \%$ & $\geq 200 \% \mathrm{RM}^{c}$ \\
\hline $\begin{array}{l}\text { Nitrogen } \\
(\mathrm{g} / \mathrm{kg})\end{array}$ & 6.5 & 2.3 & 10.6 & $34 \%$ & $<30 \% \mathrm{RM}$ \\
\hline $\mathrm{C} / \mathrm{N}$ & 29.6 & 17.6 & 65.2 & $39 \%$ & $>8$ \\
\hline $\mathrm{P}_{2} \mathrm{O}(\mathrm{g} / \mathrm{kg})$ & 2.9 & 1.7 & 6.3 & $32 \%$ & $<30 \% \mathrm{RM}$ \\
\hline $\mathrm{K}_{2} \mathrm{O}(\mathrm{g} / \mathrm{kg})$ & 11.9 & 4.1 & 21.4 & $43 \%$ & $<30 \% \mathrm{RM}$ \\
\hline $\mathrm{MgO}(\mathrm{g} / \mathrm{kg})$ & 0.7 & 0.3 & 1.7 & $37 \%$ & \\
\hline $\mathrm{CaO}(\mathrm{g} / \mathrm{kg})$ & 3.6 & 1.2 & 5.7 & $40 \%$ & \\
\hline $\begin{array}{l}\mathrm{Copper} \\
(\mathrm{g} / \mathrm{kg})\end{array}$ & 19 & 3 & 43 & $60 \%$ & \\
\hline $\begin{array}{l}\text { IOMS } \\
(\% O M)\end{array}$ & 48 & 27 & 63 & $22 \%$ & \\
\hline
\end{tabular}

a Limit values of the NF U 44-051 [5].

${ }^{\mathrm{b}}$ Value situated apart of the limit value of the NF U 44-051 [5]

${ }^{c} \mathrm{RM}$ : Raw matter.

Alsace. Conclusions of these two studies are similar. No vintage effect is observed: the variation between the minimum and the maximum values are comparable for the three years. Analytical results were compared with the limit values of the mandatory standard on organic amendments (NF U 44-051) [5]. The 22 grape marc specimens analyzed respect the NF U 44-051 standard criteria on trace metals, organic traces, inert and impurities and microbiological criteria. Among the 22 specimens analyzed, 3 do not meet the standard for dry matter content (dry matter content and agronomic composition of grape marc vary depending on the winemaking processes). The $\mathrm{pH}$ of grape marc is acid: the 22 specimens analyzed have a $\mathrm{pH}$ below 6.5 which is the minimum specified by regulatory requirement (arrêté du 26 novembre 2012 relatif aux ICPE soumises à enregistrement de la rubrique 2251 [6]). The IOMS values (Index of Organic Matter Stability) correspond to moderately stable products (cf. Table 1).

\subsubsection{What agronomic interest?}

The wealth of minerals is quite comparable to that of manure, but with higher potassium and lower magnesium levels, which causes an imbalance in the vineyard. Depending on the soil characteristics and culture, a magnesium supplement is to be expected in case of grape marc spreading. The grape marc IOMS average values (Index of Organic Matter Stability) correspond to manure values, and are lower than manure composts values (average around 70) or green wastes composts values (average around 80).

The results of nitrogen and carbon mineralization show that nitrogen is organized, that is to say micro-organisms use the soil nitrogen to degrade grape marc (available grape marc nitrogen is not enough). This can be interpreted as a risk of nitrogen starvation. This effect is less important on white grape marc.

Soil analysis, before and after spreading, have been realized on three arable crops parcels where grape marc had been spread on September 2011. Grape marc spreading causes few modifications of soil analytic characteristics, particularly concerning trace metals.

\subsection{Grape marc composting}

\subsubsection{What agronomic interest?}

Analysis of grape marc composts, alone or co-composted with manure or green wastes (up to maximum $80 \%$ ), indicate that these products generally have characteristic similar to organic amendments, as defined in NF U 44051 [5]. However, dry matter content can be lower than the standard limit (1 case), and K2O content can be higher (1 case). In the case of a compost containing grape marc and manure $(50 \%)$, we see a presence of pathogenic organisms (Helminths eggs) which is caused by the manure, and Escherichia coli and Enterococcus thresholds higher than specified in the NF U 44-051 standard and regulatory requirements on animal by-products.

IOMS values (Index of Organic Matter Stability) correspond to green wastes composts values. Results of nitrogen mineralization are similar to those measured for the grape marc spreading tests: nitrogen is organized, that is to say micro-organisms use the soil nitrogen to degrade grape marc compost (available grape marc compost nitrogen is not enough).

However, in contrast to the measures realized for grape marc spreading tests, a net mineralization is then observed for composts: after the organizational phase, nitrogen is released from the compost. The amount of released nitrogen is higher than the one consumed by microorganisms during the organization phase. As in the case of non-composted grape marc, potassium levels are very high compared to magnesium levels. The same precautions are recommended: depending on soil characteristics and culture, a magnesium supplement is to be expected in case of grape marc compost spreading.

\subsubsection{Organizational feasibility}

The presence of a co-substrate leads to faster increase in temperature compared to compost containing only grape marc. Mixtures (grape marc and co-substrate) reach $66^{\circ} \mathrm{C}$ in 4-5 days; composts containing only grape marc reach $50^{\circ} \mathrm{C}$ after 3 weeks. Little difference is observed between the temperature curves concerning the temperature rise (fermentation phase). However, the temperature rise of the compost mostly containing grape marc (75\%) is slower. Moreover, while the compost containing only distilled grape marc rapidly reach the maturation phase (after 4 weeks), the composts containing grape marc have a longer fermentation phase (37 weeks).

\subsection{Grape marc anaerobic digestion}

\subsubsection{What methane potential?}

Methane potential is the maximum quantity of biogas and methane ( $\mathrm{CH} 4)$ which can be produced by a substrate. It 
can be expressed in $\mathrm{ml} \mathrm{CH} 4$ / g VM (volatile matter) or in $\mathrm{ml} \mathrm{CH} 4$ / g RM (raw matter). The raw matter is the mass of the product which enters in the anaerobic digestion installation; the volatile matter is the organic part of the raw matter capable to be degraded by the anaerobic microorganisms.

The methane potential of the 4 specimens of grape marc and 2 specimens of distilled grape marc has been measured by a conventional methane potential test without lyophilization. The results show variability in methane potential depending on color, origin and storage time (cf. Table 2).

\subsubsection{Organizational feasibility?}

A grape marc anaerobic digestion test has been conducted at an industrial scale during the 2011 and 2012 campaigns in Alsace. Grape marc has been treated in co-digestion together with cattle manure, whey, silage, molasses and organic wastes from restaurants, supermarkets and hypermarkets. The daily ration varies between 70 and 90 tons. Grape marc from the 2011 campaign (1 500 tons) has been incorporated to the mixture from January to May of 2012. Grape marc from the 2012 campaign has been incorporated to the mixture from September 2012. The proportion of grape marc in the total mixture ranges from 6-33\%.

\section{Economic aspects}

The economic diagnosis aims to identify investment costs, operating costs, and value of products, for every recovery method of grape marc, from the output of the press until its final recovery. The study proposes to identify the main expenditure items which winegrowers confront (or could confront) for every recovery method and every scenario. Before the step of costing, scenarios have been developed: the volumes treated, the way of treatment (internal or external by a service provider) and the technical and regulatory aspects do vary the costs. Costs presented refer to the recovery of 1 ton of grape marc, for every recovery method and every scenario. Operators have been differentiated into two distinct categories in terms of scale: individual or collective. The scenarios about the recovery of 30 tons of grape marc refer to individual cellars (individual scale); the scenarios about the recovery of 300 tons of grape marc refer to cooperative and individual cellars (collective scale).

\subsection{Distillation and its by-products}

For wine makers, grape marc transport costs logically vary depending on the distance. The economic study showed it can vary from 7 to $25 € /$ t. In most cases, because of the financial support for transport (paid to the wine maker when he realizes the transport) and for transformation, transport and recovery of the oenological by-products by wine distilleries are zero cost for wine makers. When a cost is paid, it is defined by wine distilleries and varies depending on the regions and the campaigns from 21 to $26 € / t$ of grape marc.

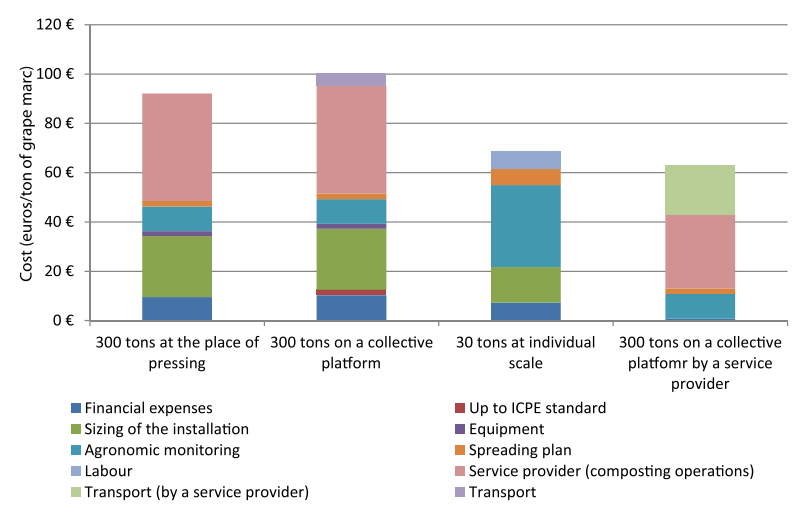

Figure 1. Detail of the grape marc composting cost per scenario (ICPE: Classified Installation for Environmental Protection).

\subsection{Grape marc spreading}

Two scenarios have been defined to evaluate the cost paid by wine makers for grape marc spreading:

- Spreading of 30 tons of grape marc at individual scale. In this scenario, the wine maker spreads grape marc on its own parcels (agricultural, vineyards or grasslands). Costs are investment costs (construction of a storage system with juices recovery, buying of a spreader, realization of a spreading plan) and operating costs (agronomic monitoring and staff cost).

In this case, the cost of the spreading of 1 ton of grape marc is $110 €$.

- Spreading of 30 tons of grape marc by a service provider. In this scenario, grape marc are bring on a collective storage platform and then spread by a service provider. The delivery is invoiced to the wine maker. Spreading plan and agronomic monitoring stay borne by the wine maker: these costs are added here. Transport costs do not appear here but are paid by the wine maker (from 5 to $20 € / \mathrm{t}$ ).

In this case, the cost of the spreading of 1 ton of grape marc is $70 €$.

\subsection{Grape marc composting}

Four scenarios have been defined to evaluate the cost paid by wine makers for grape marc composting:

- Composting 300 tons of grape marc at the place of pressing.

- Composting 300 tons of grape marc on a collective platform.

- Composting 30 tons of grape marc at individual scale.

- Composting 300 tons of grape marc on a collective platform by a service provider.

Grape marc composting has been defined as cocomposting with $50 \%$ of crushed green wastes. The cost of green wastes delivery has not been included in the calculation.

The cost of the composting of 1 ton of grape marc varies from 63 to $100 €($ cf. Fig. 1). 
Table 2. Methane potential of 4 specimens of grape marc and 2 specimens of distilled grape marc.

\begin{tabular}{|c|c|c|c|c|c|c|}
\hline \multirow[b]{2}{*}{ Grap marc } & \multirow[b]{2}{*}{ Color } & \multirow[b]{2}{*}{ Vintage } & \multirow[b]{2}{*}{$\begin{array}{c}\mathrm{RM} \\
\text { content } \\
\%\end{array}$} & \multirow[b]{2}{*}{$\begin{array}{c}\mathrm{VM} \\
\text { content } \\
\%\end{array}$} & \multicolumn{2}{|c|}{$\begin{array}{l}\text { Methane } \\
\text { potential }\end{array}$} \\
\hline & & & & & $\begin{array}{c}(\mathrm{ml} \\
\mathrm{CH} 4 / \mathrm{g} \\
\text { of } \mathrm{VM})\end{array}$ & $\begin{array}{c}\mathrm{ml} \\
\mathrm{CH} 4 / \mathrm{g} \\
\text { of } \mathrm{RM})\end{array}$ \\
\hline \multirow{2}{*}{ After pressing } & White & 2011 & 34.9 & 32.5 & 260 & 85 \\
\hline & Red & 2012 & 53.2 & 49.4 & 165 & 81 \\
\hline Ensiled 2years & \multirow{2}{*}{ White } & 2010 & 32.3 & 28.1 & 206 & 58 \\
\hline Ensiled 1 year & & 2011 & 35 & 30.7 & 148 & 46 \\
\hline \multirow{2}{*}{$\begin{array}{l}\text { Distilled and ensiled } \\
3 \text { mois Seedless } \\
\text { Not seedless }\end{array}$} & \multirow[t]{2}{*}{ Mix of white and red } & 2012 & 31.2 & 28.6 & 131 & 37.5 \\
\hline & & & 35.9 & 33.5 & 118 & 39.5 \\
\hline
\end{tabular}

\subsection{Grape marc anaerobic digestion}

The cost of grape marc anaerobic digestion is evaluated from two factors: transport cost and treatment cost. The amounts vary depending on the volume of grape marc treated, the travelled distance between the place of pressing and the anaerobic digestion installation, the specific characteristics of each region, etc.

Transport costs vary from 5 to $25 € /$ t. The average treatment cost is $58 € / t$. Because of regional specificities, this cost can be zero.

Four scenarios have been defined:

- An individual cellar that produces 30 tons of grape marc. The cellar bears transport and treatment costs.

- An individual cellar that produces 30 tons of grape marc. The cellar only bears transport cost.

- A cooperative cellar that produces 300 tons of grape marc. The cellar bears transport and treatment costs.

- A cooperative cellar that produces 300 tons of grape marc. The cellar only bears transport cost.

The cost of the anaerobic digestion of 1 ton of grape marc varies from 20 to $82.5 €$.

\section{Environmental aspects}

The Life Cycle Assessment method (LCA) has been implemented to evaluate the environmental impact of the treatment of 1 ton of grape marc by each recovery method. The LCA consists of the quantification of incoming (raw material, water, energy) and outgoing flows (wastes, emissions) of a system and then in the translation of these flows in environmental impacts. It is a global method: multi-stages (taking into account all the life stages of the studied system) and multi-criteria (evaluation of several environmental impacts). LCA is internationally recognized and defined by the ISO 14040 standard.

The 4 environmental indicators considered in this study are:

- harm to human health (caused by toxic and carcinogenic emissions for instance),

- ecosystems quality (eco-toxicity, acidification, eutrophication...),

- climate change (caused by greenhouse gas emissions),

- depletion of non-renewable resources (fossil or mineral).

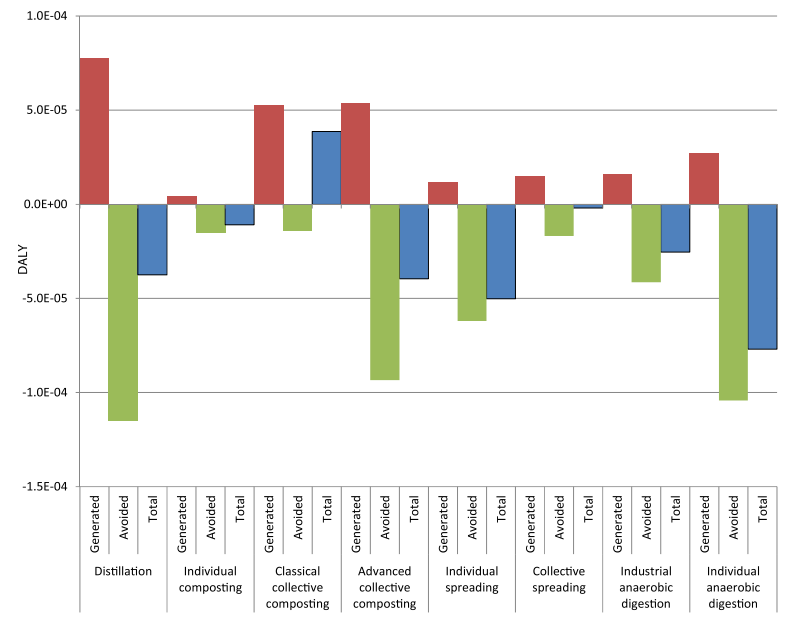

Figure 2. Comparative LCA results on the human health indicator.

The result for each recovery method is the evaluation of the potential impact caused on the environment for each indicator. These impacts can be generated or avoided. The avoided impacts can be explained by the substitution principle: we consider for instance that obtaining recycled products avoids the production via a "classical" industrial way. Thereby, when an oenological by-products recovery method allows a material (amendment, chemical, feeding...) or energy (bioethanol, biogas...) recovery, avoided impacts are considered.

This study has been submitted to a critical review. A college of 3 independent experts validated the choices, examined the coherence of the method and the life cycle inventory. Following this critical review, the LCA has been certified as conforming to the ISO 14040 standard.

The results obtained for the recovery of 1 ton of grape marc by distillation, anaerobic digestion, composting and spreading are presented in the Figs. 2 to 5 . Generated impacts are represented by red bars and avoided impacts by green bars. The result is represented by a blue bar.

\subsection{Human health indicator}

Distillation and collective composting are the scenarios which generate the higher impacts. Spreading and anaerobic digestion generate a lower impact on this 


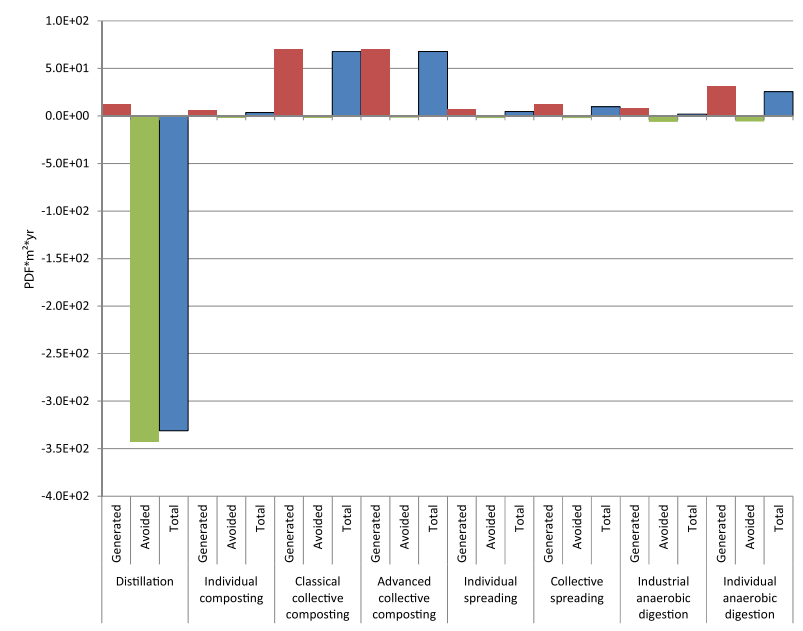

Figure 3. Comparative LCA results on the ecosystems quality indicator.



Figure 4. Comparative LCA results on the climate change indicator.

indicator. Individual composting generated the smallest impact.

Avoided impacts are very close to each other; but we note that distillation and industrial anaerobic digestion scenarios have stronger avoided impacts.

The result of these generated and avoided impacts is a negative score for all scenarios, excepted for the classical collective composting one. Individual spreading and industrial anaerobic digestion have the best results concerning the human health indicator.

\subsection{Ecosystems quality indicator}

The two collective composting scenarios (classical and advanced) generate the stronger impacts on the ecosystem quality indicator. Distillation, spreading and anaerobic digestion scenarios generate a lower impact on this indicator.

Distillation is the scenario with the higher avoided impacts. The other scenarios have avoided impacts close to each other.

The result of these generated and avoided impacts is a very favorable score for the distillation scenario. In contrast, generated impacts are higher than avoided ones

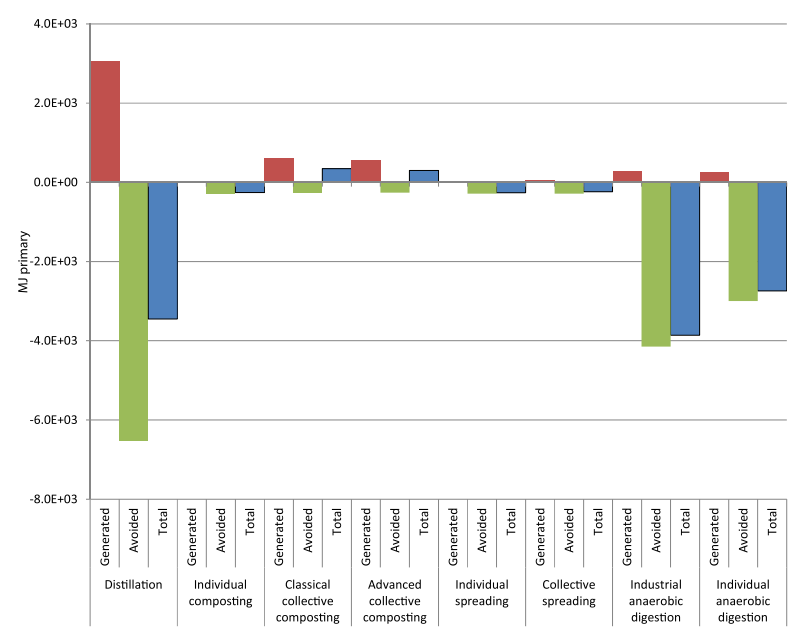

Figure 5. Comparative LCA results on the resources indicator.

for all the others scenarios concerning the ecosystems quality indicator.

\subsection{Climate change indicator}

Distillation and composting scenarios generate the higher impacts. Spreading and anaerobic digestion scenarios generate a lower impact on this indicator.

Industrial anaerobic digestion and distillation allow avoiding most of the impacts. The others scenarios (spreading, composting and individual anaerobic digestion) also have avoided impacts but lower.

The result of these generated and avoided impacts is a negative score for all scenarios, excepted for collective composting ones. The most favorable scores concern individual anaerobic digestion, distillation and industrial anaerobic digestion. The other scenarios have scores very close to each other.

\subsection{Resources indicator}

Distillation is the scenario which generates highest impact. Spreading, composting and anaerobic digestion scenarios generated a lower impact on this indicator. The impacts generated by individual composting and spreading are close to each other.

Distillation and anaerobic digestion scenarios present the highest avoided impacts. The other scenarios present scores very close to each other.

The result of these generated and avoided impacts is a very favorable score for distillation and anaerobic digestion scenarios. This score is also favorable for spreading and individual composting scenarios. In contrast, generated impacts are higher than avoided ones for the collective composting scenario.

\section{Conclusion}

The national experimentation about oenological byproducts recovery, which ran from 2010 to 2013, studied the recovery of grape marc and wine lees by distillation (only recovery method established and authorized before 2014), and 3 forward-looking scenarios: spreading, composting and anaerobic digestion of grape 
marc. Results are outcome of tests realized at several scales (laboratory, individual scale, production region) and in several production regions.

Since August the 18th of 2014, composting and anaerobic digestion of grape marc and wine lees, and spreading of grape marc are authorized in France. The results presented above will have to be completed and consolidated with monitoring and observation of the new recovery sectors which will be developed in the coming months.

\section{References}

[1] Règlement (CE) $\mathrm{n}^{\circ} 1234 / 2007$ du Conseil du 22 octobre 2007 portant organisation commune des marchés dans le secteur agricole et dispositions spécifiques en ce qui concerne certains produits de ce secteur
[2] Décret n²014-903 du 18 août 2014 relatif à la valorisation des résidus de la vinification

[3] Arrêté du 18 août 2014 relatif aux modalités de déclaration et de contrôle de la valorisation des résidus de la vinification

[4] V. Lempereur, S. Penavayre, Marcs de raisins, lies de vin et bourbes : Quelle gestion des sous-produits vinicoles ? Institut Français de la Vigne et du Vin, Cahier Itinéraires $\mathrm{n}^{\circ} \mathbf{2 5}$ (novembre 2013)

[5] NF U44-051, Amendements organiques Dénominations, spécifications et marquage (avril 2006)

[6] Arrêté du 26 novembre 2012 relatif aux prescriptions générales applicables aux installations relevant du régime de l'enregistrement au titre de la rubrique 2251 (préparation, conditionnement de vins) de la nomenclature des installations classées pour la protection de l'environnement 